\title{
VARIATION OF ISOENZYME AND RAPD PATTERNS IN CANDIDA ALBICANS MORPHOLOGICAL MUTANTS WITH ALTERED COLONY ULTRASTRUCTURE*
}

\author{
M. Pesti, ${ }^{1 * *}$ Cs. VÁgvölgyi, ${ }^{2}$ T. PAPp, ${ }^{2}$ A. NAgY ${ }^{2}$ and A. NováK ${ }^{1}$ \\ ${ }^{1}$ Department of General and Environmental Microbiology, Institute of Biology, Faculty of Sciences, \\ University of Pécs, H-7624 Pécs, P. O. Box 266, Hungary \\ ${ }^{2}$ Department of Microbiology, Faculty of Sciences, University of Szeged, \\ H-7601 Szeged, P. O. Box 533, Hungary
}

(Received: August 31, 2000; accepted: October 5, 2000)

\begin{abstract}
Molecular typing methods were applied to characterize four stable morphological mutants [1] isolated from a UV-induced unstable mutant colony of Candida albicans. The wild-type strain (ATCC 64385), the intermediate unstable mutant and its four morphologically altered derivatives revealed the same electrophoretic karyotypes. Of the five isoenzymes tested (catalase, malate dehydrogenase, glutamate dehydrogenase, acid phosphatase and $\beta$-glucosidase), glutamate dehydrogenase displayed a different enzyme pattern (with an extra band of lower mobility) in the morphological mutants. In contrast, the random amplification DNA polymorphism patterns of the mutant strains differed in all cases from that of the parental strain. Different primers revealed various degrees of DNA polymorphism; one of them (OPC-8) proved to be useful for differentiation between all examined strains. Differences in genetic alterations between spontaneous and induced mutants, and the applicability of different molecular markers to analyse the consequences of induced mutagenesis in C. albicans are discussed.
\end{abstract}

Keywords: Candida - morphogenesis - RAPD

\section{INTRODUCTION}

Candida albicans is known to grow as a budding yeast, producing smooth colonies on substrate-rich media. It has the ability to undergo a dimorphic transition in response to special environmental factors and reversible high-frequency, straindependent phenotypic switching $[18,26]$. Spontaneous colony morphology variants have also been observed on rich media. Genetic analysis and the application of different molecular typing methods have revealed that this variability is a consequence of genomic instability, mutations resulting in an altered ploidy [22, 27], karyotype [25] or polymerase chain reaction (PCR) type [29]. Spontaneous morphological mutants, most of them originating from clinical material, also exhibit variations in antifungal sensitivity [7] and pathogenicity [22, 27].

Induced mutagenesis combined with enrichment methods and somatic hybridisation allows the investigation of different aspects of the morphogenesis of this diploid,

\footnotetext{
*Dedicated to Professor Lajos Ferenczy on the occasion of his 70th birthday.

**Corresponding author; e-mail: micro@ttk.pte.hu
} 
naturally heterozygous imperfect pathogen [14, 22]. Morphological mutants unable to produce hyphae [3, 7], mycelial and pseudomycelial mutants $[5,10]$, and mutants affected in cell wall synthesis [19] have been obtained from C. albicans. When protoplast fusion was applied to produce somatic hybrids, their analyses defined two complementation groups representing two genes relevant for dimorphism: alterations of these interfered with the correct transition from blastospores to mycelium [5]. In other crossing experiments, the examined mutations were different and recessive [6]. Results relating to the cytological analysis and antifungal sensitivity of these mutants and their hybrids have been reported, but no information is available as concerns alterations at a molecular level.

The purpose of the present work was to characterize four UV-induced stable morphological mutants of $C$. albicans by molecular typing methods, and to compare these results with earlier findings. Preliminary data from this project were presented at the 13th Congress of the International Society for Human and Animal Mycology [21].

\section{MATERIALS AND METHODS}

\section{Strains and culture conditions}

Four stable morphological mutants were isolated as segregants from a star-shaped colony obtained after UV-mutagen treatment of the wild-type strain C. albicans ATCC 64385. The isolation and morphological characterization of these mutants were performed as described earlier [1]. They were maintained on yeast extract-peptone-glucose medium (yeast extract $3 \mathrm{~g} \mathrm{l}^{-1}$, peptone $5 \mathrm{~g} \mathrm{l}^{-1}$, glucose $10 \mathrm{~g} \mathrm{l}^{-1}$, and Bacto agar $\left.20 \mathrm{~g} \mathrm{l}^{-1}, \mathrm{pH} 6.5\right)$.

Saccharomyces cerevisiae strain YP80 was used as a standard strain for molecular typing.

\section{Isoenzyme analysis}

The preparation of crude protein extracts and polyacrylamide gel electrophoresis were performed as described earlier [30], with the modification that $7.5 \%$ separation gels and 3.5\% stacking gels were applied. The activities of the following five enzymes were investigated: catalase (CAT; EC1.11.1.6) [32], malate dehydrogenase (MDH; EC 1.1.1.14) [2], glutamate dehydrogenase (GDH; EC 1.4.1.4) [1], acid phosphatase (ACP; EC 3.1.3.2) [8] and $\beta$-glucosidase (GLU; EC 3.2.1.21) [9].

\section{RAPD analysis and electrophoretic karyotyping}

The rapid lithium chloride procedure [12] was used to isolate total DNA for RAPD reactions. Amplification of template DNA was carried out as described by Williams 
et al. [31] with slight modifications. For amplifications, a denaturation step at $94{ }^{\circ} \mathrm{C}$ for 4 min, followed by 1 cycle at $38^{\circ} \mathrm{C}$ for $1 \mathrm{~min}$ and $72{ }^{\circ} \mathrm{C}$ for $1 \mathrm{~min}$, and then 35 cycles at $94{ }^{\circ} \mathrm{C}$ for $1 \mathrm{~min}$, at $38^{\circ} \mathrm{C}$ for $1 \mathrm{~min}$ and at $72^{\circ} \mathrm{C}$ for $1 \mathrm{~min}$. The final cycle concluded with an extension step at $72{ }^{\circ} \mathrm{C}$ for $7 \mathrm{~min}$. DNA from each strain was amplified with four different 10-base primers (Operon). Nucleotide primers and their sequences $\left(5^{\prime} \rightarrow 3^{\prime}\right)$ were as follows: OPC-01 (TTCGAGCCAG), OPC-08 (TGGACCGGTG), OPC-13 (AAGCCTCGTC) and OPC-19 (GTTGCCAGCC). Ten $\mu 1$ of each amplification reaction was separated by electrophoresis on $1.4 \%$ agarose/TBE gels.

Protoplast formation, preparation of chromosomal samples and separations were performed as described earlier [16].

\section{RESULTS}

\section{Colony types}

The investigated colony types of four stable morphological mutants are depicted in Fig. 1a-d. The macroscopic appearance, the ultrastructure and the cell types of colonies of the wild-type strain, its UV-induced unstable star-shaped mutant derivative and its regular-wrinkled (Fig. 1a) and irregular-wrinkled (Fig. 1b) stable segregants were characterized in detail earlier by scanning electron microscopy (SEM) [1].

A further two stable morphological mutants (Fig. 1c-d) were involved in the present molecular typing experiments. Colonies of both of them contained $43 \%$ hyphae, $18 \%$ pseudohyphae and 39\% blastospores. However, no atypical hyphae structures were observed. A representative SEM image of the central part of the surface of these colonies can be seen in Fig. 1e. In spite of the differences in the colony appearance (Fig. 1c-d), the internal ultrastructures of the colonies were very similar, exhibiting nearly the same organisation as for the irregular-wrinkled colonies [20].

\section{Isoenzyme analysis}

The isoenzyme patterns of five enzyme systems were studied. All six examined $C$. albicans strains exhibited similar patterns for ACP, CAT, GLU and MDH. When CAT staining was used, the $C$. albicans strains gave the same pattern as that for S. cerevisiae strain YP80 used as an outgroup strain for comparison (Fig. 2). Only the GDH pattern of the wild-type parental strain was different from those observed for the colony morphology mutants (including the intermediate star-shaped one). For these mutants, an extra band with lower mobility was detected (Fig. 3). 


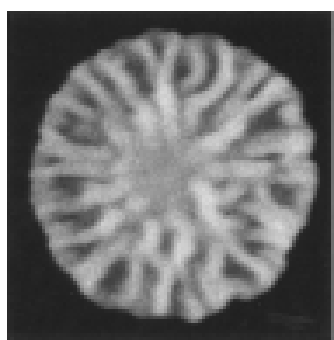

a

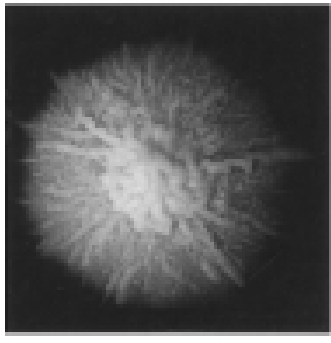

c

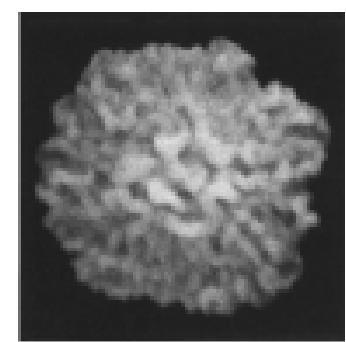

b

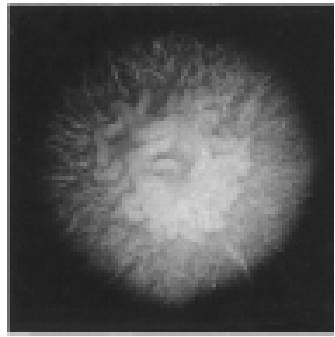

d

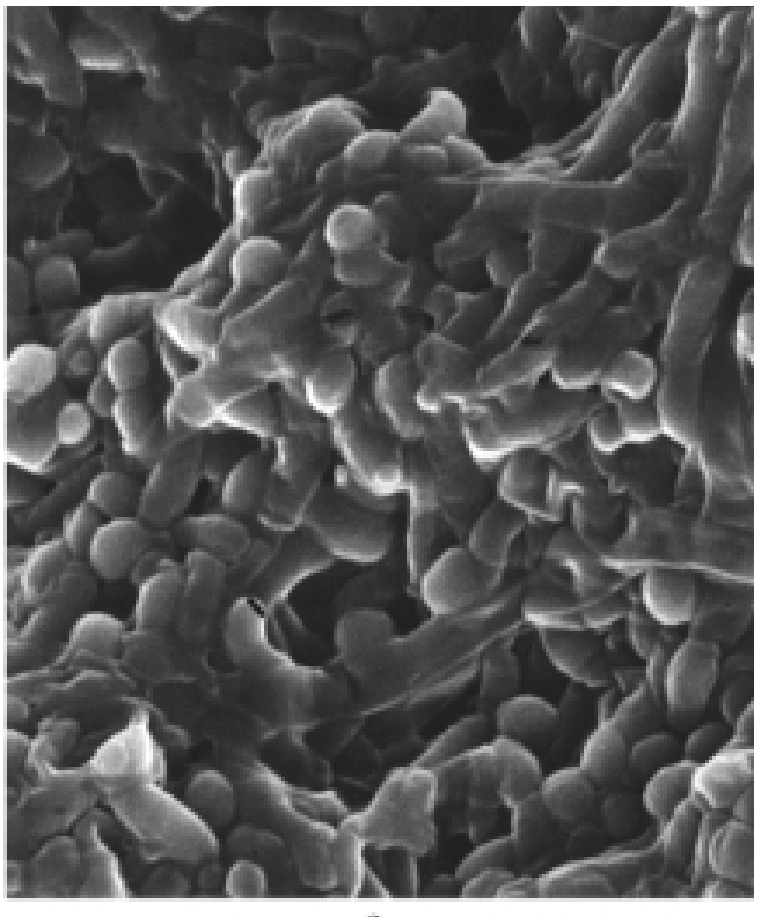

e

Fig. 1. Colonies of four stable C. albicans morphological mutants: regular-wrinkled (a), irregular-wrinkled (b), echinoid (c) and frilly (d). Representative SEM (e) from the middle of the surface of the echinoid mutant colony $(\times 1100)$

Acta Biologica Hungarica 52, 2001 

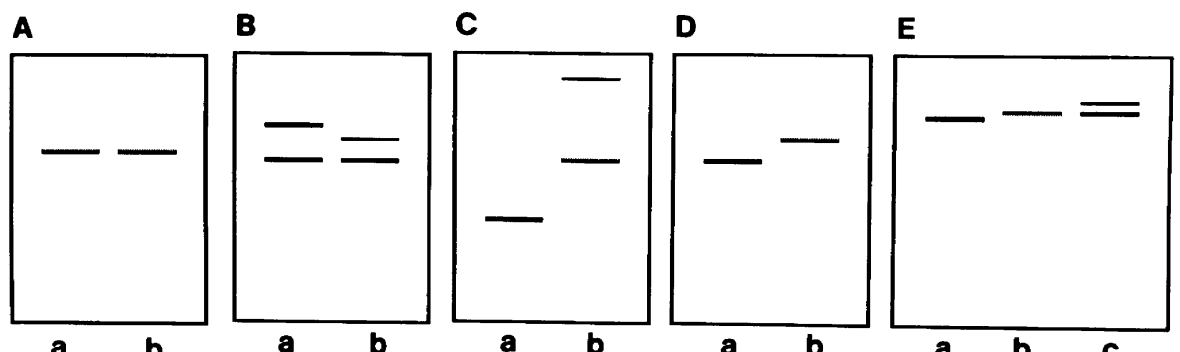

Fig. 2. Diagrammatic representation of the observed isoenzyme patterns: S. cerevisiae YP80 (a), C. albicans ATCC 64385 (b) and its morphological mutants (c)

$\begin{array}{lll}1 & 2 & 3\end{array}$

Fig. 3. Glutamate dehydrogenase patterns associated with wild-type and mutant strains. Lanes 1-3, S. cerevisiae YP80, C. albicans ATCC 64385 and its morphological mutant derivatives, respectively

\section{Electrophoretic karyotyping and RAPD analysis}

The six C. albicans strains revealed the same electrophoretic karyotype (results not shown) as that characteristic of the original wild-type strain [17]. Four arbitrary sequences (OPC-01, OPC-08, OPC-13 and OPC-19) resulted in detectable amplifications in RAPD reactions. Representative amplification patterns with the primer 


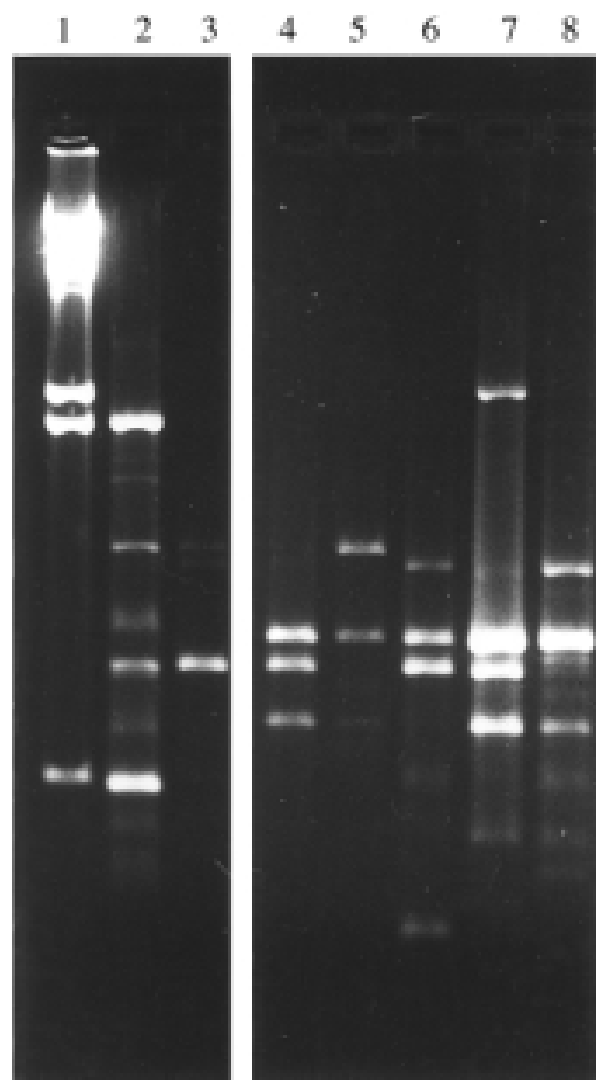

Fig. 4. Agarose gel electrophoresis showing PCR products after use of the primer OPC-08. Lane 1: Hind III-digested $\lambda$ DNA. Lanes 2-8: amplification patterns from $S$. cerevisiae YP80, C. albicans ATCC 64385 , its star-shaped, regular-wrinkled, irregular-wrinkled, echinoid and frilly mutant derivatives, respectively

Table 1

RAPD amplification types (Fig. 5) detected in C. albicans wild-type and mutant strains

\begin{tabular}{lcccc}
\hline & OPC-01 & OPC-08 & OPC-13 & OPC-19 \\
\hline 04 (wild-type) & $\mathrm{a}$ & $\mathrm{a}$ & $\mathrm{a}$ & $\mathrm{a}$ \\
073 (star-shaped) & $\mathrm{c}$ & $\mathrm{b}$ & $\mathrm{d}$ & $\mathrm{b}$ \\
$073 /$ F (irregular-wrinkled) & $\mathrm{b}$ & $\mathrm{c}$ & $\mathrm{b}$ & $\mathrm{b}$ \\
$073 /$ W (regular-wrinkled) & $\mathrm{d}$ & $\mathrm{d}$ & $\mathrm{c}$ & $\mathrm{b}$ \\
$073 /$ S (echinoid) & $\mathrm{b}$ & $\mathrm{e}$ & $\mathrm{d}$ & $\mathrm{b}$ \\
$073 /$ Cs (frilly) & $\mathrm{b}$ & $\mathrm{f}$ & $\mathrm{d}$ & $\mathrm{c}$
\end{tabular}



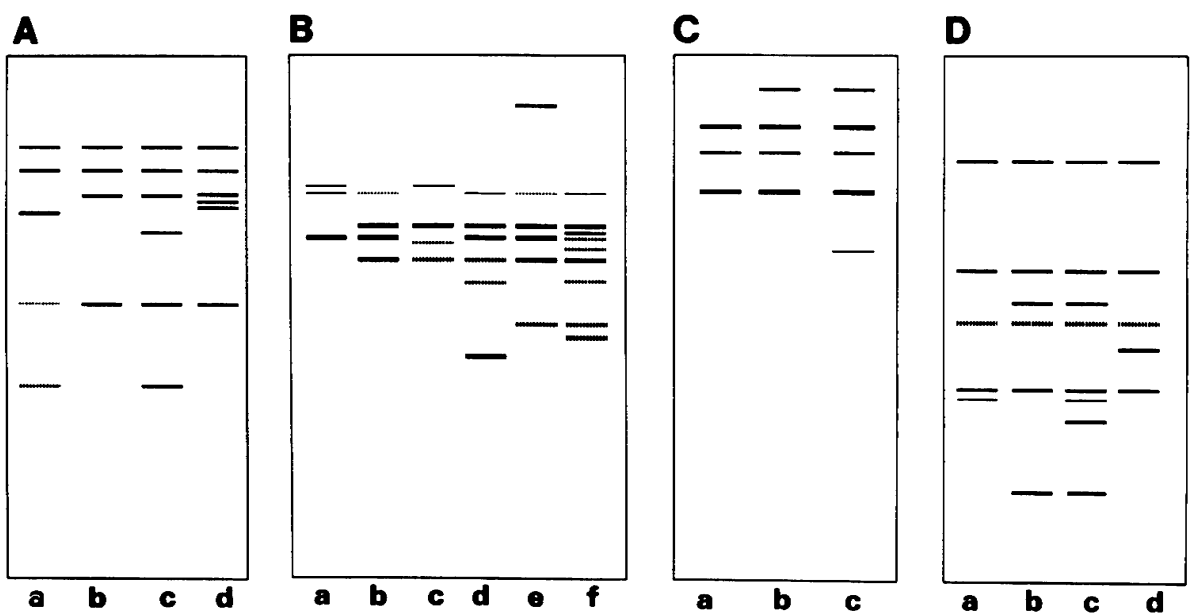

Fig. 5. Diagrammatic representation of the RAPD amplification patterns obtained with primers OPC01(A), OPC-08(B), OPC-19(C) and OPC-13(D). The corresponding amplification types are summarised in Table 1

OPC- 08 are to be seen in Fig. 4. The number of reproducible amplified bands of the six examined C. albicans strains varied between 4 and 9 in different reactions. The sizes of the detected amplification products were between 0.51 and $8.35 \mathrm{~kb}$. In contrast with the isoenzyme similarity of the parental strain and its five morphological mutants, the RAPD amplification patterns of these mutants differed from that of the wild-type strain in all cases (Fig. 5). Different primers revealed different degrees of DNA polymorphism of the morphological mutants: two (OPC-19), three (OPC-01 and $\mathrm{OPC}-13$ ) or five (OPC-08) new amplification patterns were detected for the random primers tested (Table 1).

\section{DISCUSSION}

The significant differences in the colony structure, ultrastructure and cell types of the four UV-induced morphological mutants examined were not reflected in the assimilation and fermentation spectra [20] and karyotype patterns, in contrast with earlier findings obtained on spontaneous [24, 27, 29] or induced [28] morphological mutants. Most $C$. albicans strains have 8 separate sets of homologue chromosomes [14], but the karyotype can vary from strain to strain because of translocations [24, 25] or other possible mechanisms of chromosomal changes [25] resulting in other karyotype patterns. In our case, it proved that mutation and segregation of the mutants did not cause detectable alterations in the karyotypes. Similar data are not available for some of the best-characterised mutagen-induced morphological mutants of $C$. albicans $[3,5,7,10]$, but the occurrence of chromosomal rearrangements associated with UV-induced C. tropicalis morphological mutation has been observed. 
Isoenzyme analysis by electrophoresis has provided a well-established and efficient tool for the revelation of genetic variability at the level of gene expression in fungal populations [23]. In the current study, isoenzyme polymorphism of the examined morphological mutants as compared to the parental strain was observed only for GDH; this is possibly a consequence of the mutation of one allele. Similar results have been published on spontaneous mutants isolated from HIV patients [23], but not on mutagen-induced morphological mutants of $C$. albicans. The greatest stability of isoenzyme markers in comparison with other biotyping methods was also suggested in the work of Lehmann et al. [13]. The background of this observation is the phenomenon that DNA-based methods such as restriction fragment length polymorphism analyses or RAPD refer more directly to the changes in the genetic material, sometimes indicating a higher level of variability among the investigated strains.

Among the morphological mutants in the current work, highly diverse amplifaction patterns have been detected by RAPD analysis. Accordingly, this approach seems to be applicable to differentiate between mutants and the wild-type strain as well as between morphological mutants. These results also suggest that an earlierinduced mutagenetic step [20], followed by a segregation and selection process for only one phenotypic character (namely colony morphology), resulted in numerous undetectable genetic alterations in the DNA. In agreement with Diaz-Guerra et al. [4], we have established that at least two different typing methods must be applied, not only if the genetic diversity of C. albicans clinical isolates is assumed, but also for the similar analyses of morphological mutants obtained by induced mutagenesis.

The genetic diversity of $C$. albicans has been intensively studied with different typing methods in recent decades [11]. Most of the isolates investigated were clinical isolates (and not well-characterised laboratory strains), which had been affected by the selection pressure of the host-parasite relationship and different types of drug treatment. Spontaneous morphological mutants were occasionally observed from this 'natural' selection, suggesting that the changes in colony morphology are indicative of a highly variable genetic background.

At the same time, morphological mutants obtained by induced mutagenesis were generally laboratory strains maintained through continuous passage. This process, especially if accompanied by selection of an auxotrophic marker, application of multiple consequtive mutagenetic steps or selection of an altered stable morphological phenotype, unambiguously favours the selection of different genotypes from those resulting from natural selection processes. In this respect, the present study provides useful preliminary results and useful molecular markers for further investigations aimed at shedding light on the molecular background of these phenomena.

\section{ACKNOWLEDGEMENTS}

We are grateful to Z. Miklovics (Department of Nuclear Medicine, University of Pécs) and É. Palotai (Department of General and Environmental Microbiology, University of Pécs) for their assistance. The contribution of Á. Nagy (Department of Microbiology, University of Szeged) in the electrophoretic karyotyping is also acknowledged. This work was supported in part by Hungarian Scientific Research Fund (OTKA) grants F 021242, D29113 and T032738. 


\section{REFERENCES}

1. Anné, J., Peberdy, J. F. (1981) Characterization of interspecific hybrids between Penicillium chrysogenum and P. roqueforti by isoenzyme analysis. Trans. Br. Mycol. Soc. 77, 401-408.

2. Brewer, G. J., Sing, C. F. (1970) An introduction to isozyme techniques. Academic Press, New York.

3. Canon, R. D. (1986) Isolation of a mycelial mutant of Candida albicans. J. Gen. Microbiol. 132, 2405-2407.

4. Diaz-Guerra, T. M., Martinez-Suarez, J. V., Laguna, F., Rodriquez-Tudela, J. L. (1997) Comparison of four molecular typing methods for evaluating genetic diversity among isolates from human immunodeficiency virus-positive patients with oral candidiasis. J. Clinic. Microbiol. 35, 856-861.

5. Gil, C., Pomés, R., Nombela, C. (1988) A complementation analysis by parasexual recombination of Candida albicans morphological mutants. J. Gen. Microbiol. 134, 1587-1595.

6. Gil, C., Pomés, R., Nombela, C. (1990) Isolation and characterization of Candida albicans morphological mutants depressed for the formation of filamentous hypha-type structures. J. Bacteriol. 172, 2384-2391.

7. Gil, C., Pérez-Diaz, R., Nombela, C. (1994) Inhibitory and morphological effects of several antifungal agents on three types of Candida albicans morphological mutants. J. Med. Vet. Mycol. 32, $151-161$.

8. Harris, H., Hopkinson, D. A. (1976) Handbook of enzyme electrophoresis in human genetics. Elsevier, Amsterdam.

9. Hills, D. M., Craig, M. (1990) Molecular systematics. Sinauer, Sunderland.

10. Hubbard, M. J., Markie, D., Poulter, R. T. M. (1986) Isolation and morphological characterization of a mycelial mutant of Candida albicans. J. Bacteriol. 165, 61-65.

11. Hunter, P. R. (1991) A critical review of typing methods for Candida albicans and their applications. Crit. Rev. Microbiol. 17, 417-434.

12. Leach, J., Finkelstein, D. B., Rambosek, J. A. (1986) Rapid miniprep of DNA from filamentous fungi. Fung. Genet. Newslett. 33, 32-33.

13. Lehman, P. F., Kemker, B. J., Hsiao, C. B., Sandesh, D. (1989) Isoenzyme biotypes of Candida species. J. Clin. Microbiol. 27, 2514-2521.

14. Magee, P. T. (1998) Analysis of the Candida albicans genome. In: Brown J. P., Tuite, M. F. (eds) Yeast gene analysis. Methods in Microbiol. Vol. 26. Academic Press, San Diego, pp. 395-415.

15. May, B. (1998) Starch gel electrophoresis of allozymes. In: Horlzel, A. R. (eds) Molecular genetic analysis of populations. Oxford University Press, Oxford.

16. Nagy, Á., Garamszegi, N., Vágvölgyi, Cs., Ferenczy, L. (1994) Electrophoretic karyotypes of Phaffia rhodozyma strains. FEMS Microbiol. Lett. 123, 315-318.

17. Navarro-Garcia, F., Perez-Diaz, R. M., Magee, B. B., Pla, J., Nombela, C., Magee, P. T. (1995) Chromosome reorganization in Candida albicans 1001 strain. J. Med. Vet. Mycol. 33, 361-366.

18. Odds, F. C. (1988) Candida and candidiosis. 2nd ed. Bailliere Tindall, London.

19. Payton, M. A., de Tiani, M. (1990) The isolation of osmotic remedial conditional lethal mutants of Candida albicans. Curr. Genet. 17, 293-296.

20. Pesti, M., Sipiczki, M., Pintér, Y. (1999) Scanning electron microscopy characterization of colonies of Candida albicans morphological mutants. J. Med. Microbiol. 48, 167-172.

21. Pesti, M., Czakó-Vér, K., Pintér, Y., Papp, T., Nagy, Á., Ferenczy, L., Vágvölgyi, Cs. (1997) Variation of colony ultrastructure, isoenzyme pattern and RAPD products in Candida albicans morphological mutants. XIII. ISHAM Congress, Parma, Italy, p. 128.

22. Pla, J., Gil, C., Monteoliva, F., Navarro-Garcia, M., Sánchez, M., Nombela, C. (1996) Understanding Candida albicans at molecular level. Yeast. 12, 1677-1702.

23. Reynes, J., Pujol, C., Moreau, C., Mallié, M., Renaud, F., Janbon, F., Bastide, J. M. (1996) Simultaneous carriage of Candida albicans strains from HIV-infected patients with oral candidiasis: multilocus enzyme electrophoresis analysis. FEMS Microbiol. Lett. 137, 269-273.

24. Rustchenko-Bulgac, E. P. (1991) Variation of Candida albicans electrophoretic karyotypes. J. Bacteriol. 173, 6586-6596. 
25. Rustchenko-Bulgac, E. P., Curran, T. M., Sherman, F. (1993) Variations in the number of ribosomal DNA units in morphological mutants and normal strains of Candida albicans and in normal strains of Saccharomyces cerevisiae. J. Bacteriol. 175, 7189-7199.

26. Soll, D. R. (1997) Gene regulation during high-frequency switching in Candida albicans. Microbiol. 143, 279-288.

27. Suzuki, T., Kobayashi, I., Kanabe, T., Tanaka, K. (1989) High frequency variation of colony morphology and chromosome reorganization in the pathogenic yeast Candida albicans. J. Gen. Microbiol. 135, 425-434.

28. Suzuki, T., Miyamae, Y., Ishida, I. (1991) Variation of colony morphology and chromosomal rearrangement in Candida tropicalis pR233. J. Gen. Microbiol. 137, 161-167.

29. Takasuka, T., Baily, G. G., Birch, M., Anderson, M. J., Lew, D., Denning, D. W. (1998) Variation in morphotype, karyotype and DNA type of fluconazole resistant Candida albicans from an AIDS patient. J. Infect. 36, 57-62.

30. Vágvölgyi, Cs., Papp, T., Palágyi, Zs., Michailides, T. J. (1996) Isozyme variation among isolates of Mucor piriformis. Mycologia. 88, 602-607.

31. Williams, J. G. K., Kubelik, A. R., Livak, K. J., Rafalski, J. A., Tingey, S. V. (1990) DNA polymorphisms amplified by arbitrary primers are useful as genetic markers. Nucleic. Acids. Res. 18, 6531-6535

32. Woodbury, W., Spencer, A. K., Stanmann, M. A. (1971) An improved procedure using ferricyanide for detecting catalase isozymes. Anal. Biochem. 44, 301-305. 